\title{
Compact Modified Swastika Shape Patch Antenna for WLAN/WiMAX Applications
}

\author{
M. Samsuzzaman, ${ }^{1}$ T. Islam, ${ }^{1}$ N. H. Abd Rahman, ${ }^{1}$ M. R. I. Faruque, ${ }^{2}$ and J. S. Mandeep ${ }^{1}$ \\ ${ }^{1}$ Department of Electronics Electrical and System Engineering, Universiti Kebangsaan Malaysia, Malaysia \\ ${ }^{2}$ Institute of Space Science, Universiti Kebangsaan Malaysia, 43600 Bangi, Selangor, Malaysia \\ Correspondence should be addressed to M. Samsuzzaman; sobuzcse@eng.ukm.my
}

Received 18 November 2013; Accepted 2 January 2014; Published 27 April 2014

Academic Editor: Rezaul Azim

Copyright @ 2014 M. Samsuzzaman et al. This is an open access article distributed under the Creative Commons Attribution License, which permits unrestricted use, distribution, and reproduction in any medium, provided the original work is properly cited.

A compact simple structure modified Swastika shape multiband patch antenna is designed and investigated. The antenna, which occupies an overall dimension of $0.305 \lambda \times 0.305 \lambda \times 0.012 \lambda$ at lower frequency, has a simple structure which comprises of a planar wide square slot in the ground with four slits and Swastika shape radiation patch with a rectangular slot. The proposed Swastika shape antenna was designed and analyzed by using a finite element method based high frequency structural simulator HFSS. The experimental and numerical results exhibit that the antenna operates over the frequency ranges $950 \mathrm{MHz}(2.28-3.23 \mathrm{GHz})$, $660 \mathrm{MHz}(3.28-3.94 \mathrm{GHz})$, and $1120 \mathrm{MHz}(5.05-6.17 \mathrm{GHz})$ suitable for WLAN $(2.4 / 5.2 / 5.8 \mathrm{GHz})$ and WiMAX $2.5 / 3.5 / 5.5 \mathrm{GHz}$ applications. It has a good omnidirectional radiation pattern and reaches $3.97 \mathrm{dBi}$ at $2.44 \mathrm{GHz}, 4.04 \mathrm{dBi}$ at $3.5 \mathrm{GHz}$, and $3.25 \mathrm{dBi}$ at the band of $5.98 \mathrm{GHz}$. A prototype is fabricated and then measured. The experimental and simulation results show good impedance bandwidth, radiation pattern, and stable gain across the operating bands.

\section{Introduction}

Recently, wireless communications have been developed widely and rapidly, which leads to a great demand in designing low-profile and multiband antennas for mobile terminals, especially the WLAN and WiMAX applications. In order to meet the wireless local area network (WLAN: 2.4-2.48, 5.155.35 , and $5.72-5.85 \mathrm{GHz}$ ) and worldwide interoperability for microwave access (WiMAX: 2.5-2.69, 3.40-3.69, and 5.25$5.85 \mathrm{GHz}$ ) standards simultaneously, multiband antennas which are integrating these two communication standards into a single device are required with good performance [1].

Many types of antennas have been proposed recently to achieve multiband and wide band functions and applications, such as [2-7]. The Double-T shaped monopole antenna was presented for only WLAN-band applications [2]. A coupled dual-U-shaped antenna was presented for only WiMAX triple-band operation [6]. Although the above antennas have many advantages, there are still some performances to be improved. For example, only two bands were involved in $[2,6]$, which limited the numbers of working modes in portable devices. The designs of the antenna may increase the cost or complexity of practical terminal design in [4] which possibly limits the integration level of the future wireless communication system. On the other hand, various types of antenna [8-14] which can both cover WLAN and WiMAX bands have attracted more and more attention in recent years: A double coupled C-shaped strips antenna [8], a circular ring and a Y-shaped strip antenna [10], L-shaped microstrip feed line and open-ended slot on the ground plane triple frequency antenna [11], a symmetrical door-shaped circular ring patch antenna [13], and triple-band microstripfed planar monopole antenna with defected ground structure [14] which have disadvantageous to some level such as incompetent well match for the whole WLAN/WiMAX bands and relatively complex structure. But they are all complicated in configuration to reduce the antenna applications.

In this study, a compact monopole patch antenna consisting of a Swastika shape patch with extra slot and wide slotted ground with four extra slots is presented in detail. The five rectangular slots in the patch radiator change the patch of the surface current. Furthermore, the slots and slits in the ground 


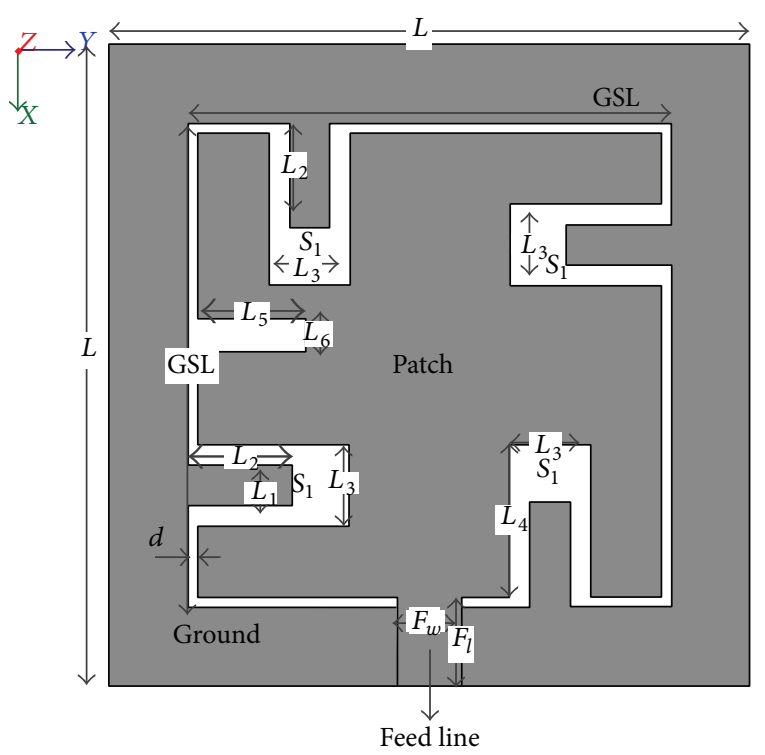

(a)

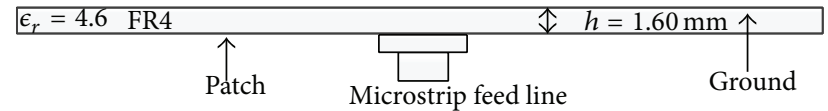

(b)

Figure 1: Proposed antenna geometry. (a) Front view. (b) Crosssectional view.

plane are also expanding the surface current. Thus, three resonant modes are excited and the dimensions of the slots and slits have an important role on matching performance of the proposed antenna. The patch radiator with microstrip line feed is printed on one side of the substrate and slotted ground plane with slits is printed on the other side of the same substrate. It can be clearly observed that the proposed patch design has a strong coupling effect with ground plane slots and slits. The simulated and measured results on the reflection coefficient and radiation pattern are also analyzed in this paper.

\section{Antenna Design Architecture}

As shown in Figure 1, the geometric configuration of the proposed antenna is designed, optimized, and fabricated on a $1.6 \mathrm{~mm}$ thick FR4 substrate with permittivity of 4.6 and a loss tangent of 0.02 . The overall size of the antenna is $40 \times 40 \times 1.6 \mathrm{~mm}^{3}$. The antenna length and width are primarily calculated from standard equation (1) [1]. The main resonator element of the proposed antenna is a Swastika shaped monopole element designed to approximately operate at centre frequency of $3.5 \mathrm{GHz}$. The wide square slot in the middle is responsible for lower band only. The other four rectangles slit with length $L_{2}$ and width $L_{1}$, respectively, which are attached in the slotted ground plane. This slit is also responsible for creating both lower and upper operating bands. An extra slit in Swastika patch is needed to achieve

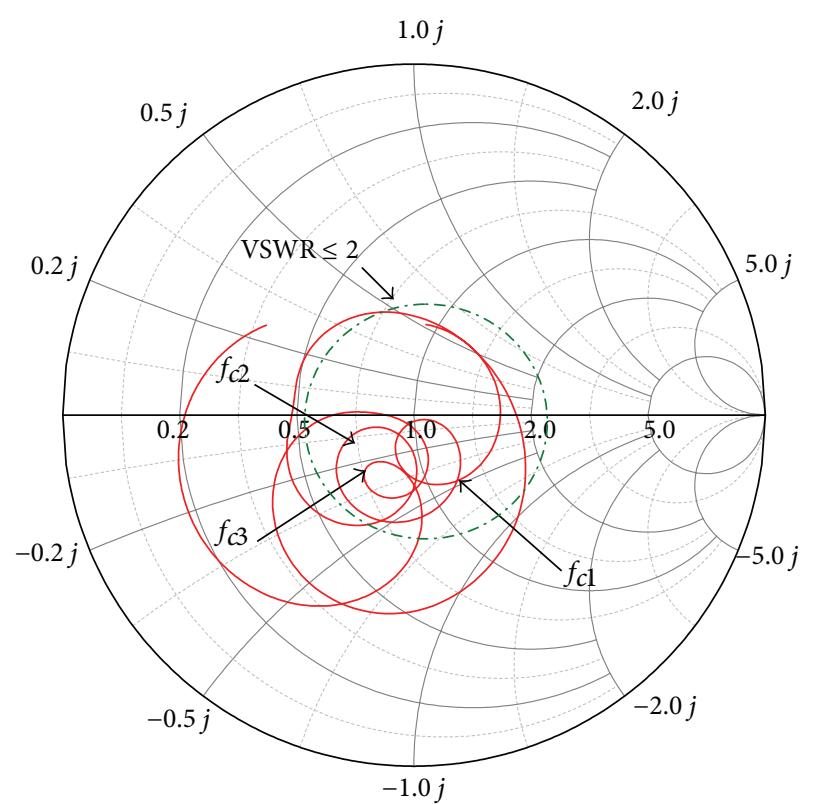

\begin{tabular}{|c|c|c|c|c|c|}
\hline Name & Freq & Ang & Mag & RX & VSWR \\
\hline$f_{\mathcal{C} 1}$ & 2.50 & 41.4652 & 0.0590 & $1.0107+0.1184 i$ & 1.1254 \\
\hline$f_{\mathcal{C} 2}$ & 3.48 & -171.0487 & 0.1293 & $0.7729-0.0316 i$ & 1.2971 \\
\hline$f_{\mathcal{C} 3}$ & 5.30 & -3.8721 & 0.0388 & $1.0806-0.057 i$ & 1.0808 \\
\hline
\end{tabular}

Figure 2: Smith chart of the proposed antenna.

the desired lower resonance. The antenna is located in $x$ $y$ plane, and the normal direction is along the $Z$-axis. To match the patch radiator to $50 \mathrm{Ohm}$ input impedance, the width and height of the feed-line are fixed at $F_{w}$ and $F_{l}$, respectively. The extra four-slit position in the ground plays a vital role to achieve the broadband characteristics of the antenna. Because the slit position is just under the patch slots, it helps match the patch radiator with the ground slits by creating a capacitive load which neutralizes the inductive nature of the patch to produce nearly pure resistive input impedance. The antenna dimensions are optimized using the commercially available simulation software of HFSS 15.0. The optimal antenna parameters are set as follows: $L=40 \mathrm{~mm}$, $L_{1}=2.5 \mathrm{~mm}, L_{2}=6.5 \mathrm{~mm}, L_{3}=5 \mathrm{~mm}, L_{4}=10 \mathrm{~mm}$, $L_{5}=6.75 \mathrm{~mm}, L_{6}=2 \mathrm{~mm}, \mathrm{GSL}=30 \mathrm{~mm}, F w=4$, $F l=5.5 \mathrm{~mm}$, and $h=1.6 \mathrm{~mm}$. Consider

$$
\begin{gathered}
f_{r}=\frac{c}{2 w_{\mathrm{eff}} \sqrt{\varepsilon_{e}}}, \\
\varepsilon_{e}=\frac{\varepsilon_{r}+1}{2}+\frac{\varepsilon_{r}-1}{2}\left(1+10 \frac{h}{w}\right)^{-1 / 2}, \\
w_{\mathrm{eff}}=w\left[1+0.824 \frac{h}{w} \frac{\left(\varepsilon_{e}+0.3\right)(w / h+0.262)}{\left(\varepsilon_{e}-0.258\right)(w / h+0.262)}\right],
\end{gathered}
$$




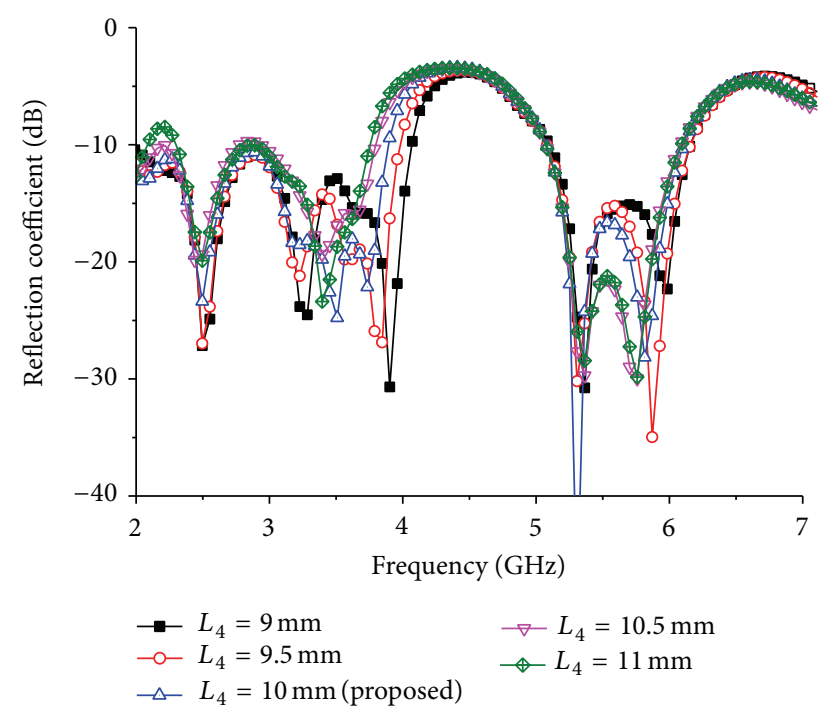

FIGURE 3: Effect of reflection coefficient for the different length of patch slot $L_{4}$.

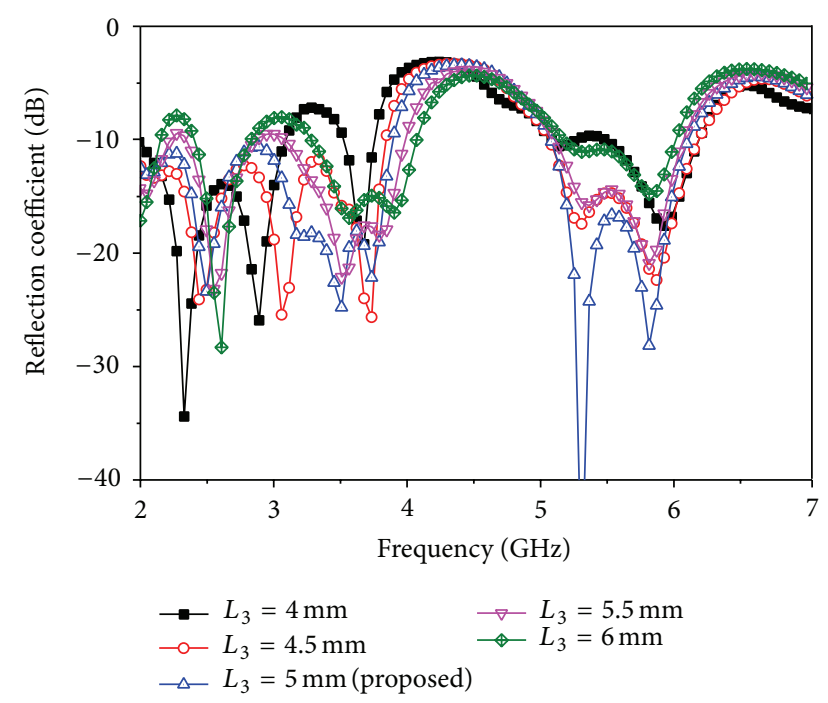

FigURE 4: Effect of reflection coefficient for the different width of patch slot $L_{3}$.

where $w$ is the side length of the square radiation patch; $w_{\text {eff }}$ is effective length; $\varepsilon_{e}$ is effective dielectric constant; and $h$ is dielectric height.

The input impedance and the voltage standing wave ratio are validated in Smith chart which is shown in Figure 2. It can be understood that three of the resonances are in the $2: 1$ VSWR circle and input impedance are close to the standard $50 \mathrm{Ohm}$. The RX values in the Smith chart table represent the input impedance. Since the curve has a tight resonant loop close to the centre of the Smith chart, which means that the proposed antenna provides a great enhancement for the impedance bandwidth. The markers $f_{c 1}$ and $f_{c 2}$ and $f_{c 3}$ represent the start and ending frequencies of the operating lower and upper operating band.

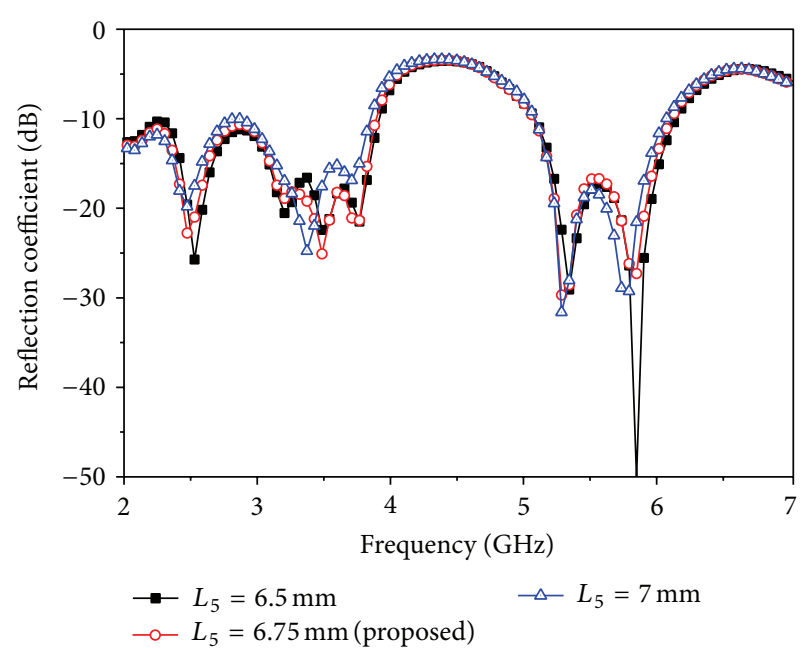

FIGURE 5: Effect of reflection coefficient for the different length of ground slit $L_{5}$.

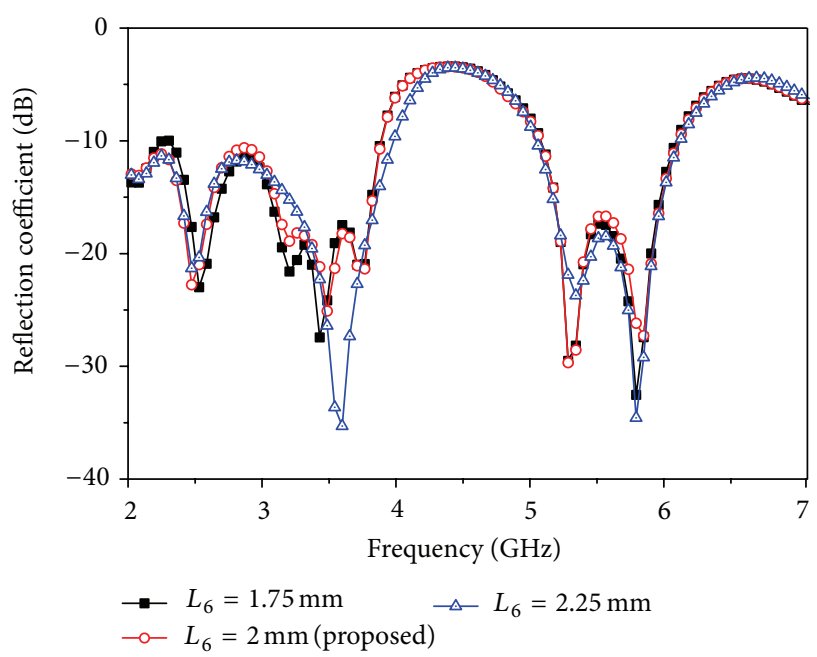

FIGURE 6: Effect of reflection coefficient for the different width of ground slit $L_{6}$.

Figures 3-8 depict the simulated reflection coefficient effect for different values of $L_{3}, L_{4}, L_{5}, L_{6}, L_{1}$, and $L_{2}$. From Figure 3 , it is observed that the lowest resonant mode is shifted to higher frequency when $L_{4}$ increased from $9 \mathrm{~mm}$ to $11 \mathrm{~mm}$. From Figure 4 , as $L_{3}$ increased from $4 \mathrm{~mm}$ to $6 \mathrm{~mm}$, the highest resonant mode return loss value is shifted to lower frequency while the other two resonant modes are barely affected. Besides, the performance of the highest resonant mode is obviously improved when $L_{3}$ increase. From Figures 5 and 6 , it can be concluded that the medial resonant mode and the highest resonant mode are not so affected. Therefore, from Figure 4, it can be stated that the three resonant modes can be obtained and tuned independently by adjusting the length and position of the three branches. Figures 7 and 8 also are responsible for achieving the desired resonance.

Figure 9 shows the reflection coefficient effect of the different feed width $F_{w}$. By increasing or decreasing the length of 


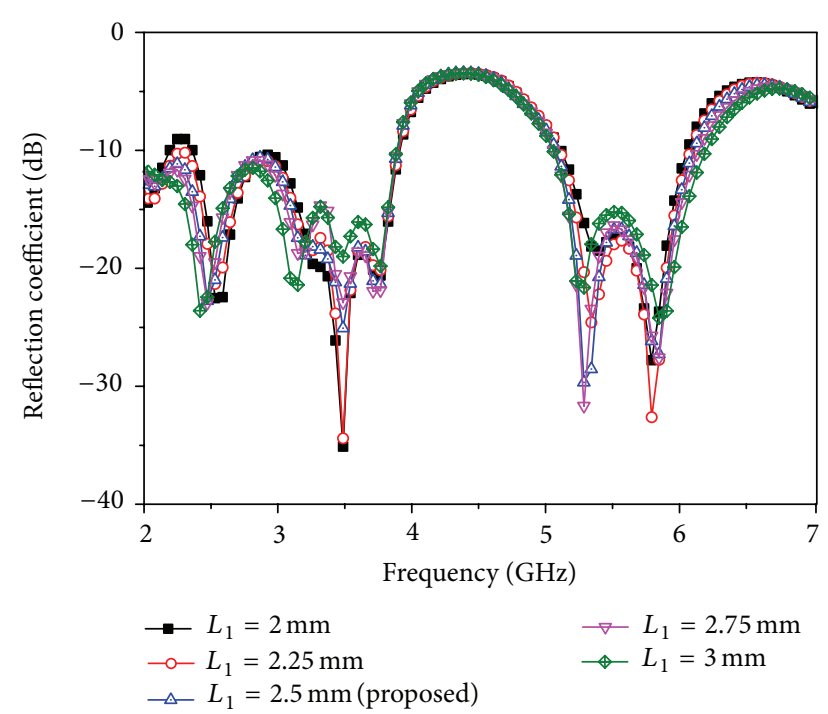

FIGURE 7: Effect of reflection coefficient for the different length of ground slit $L_{1}$.

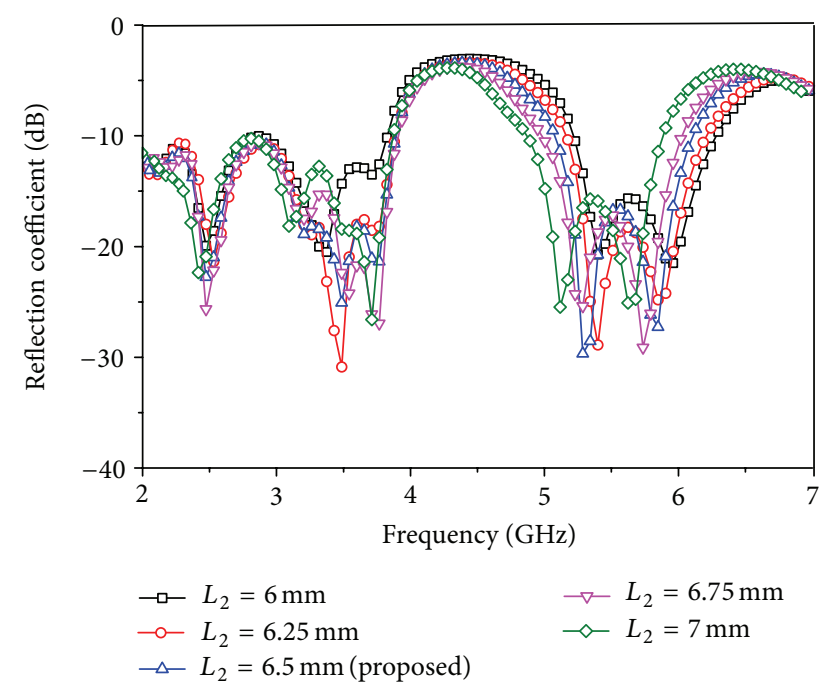

Figure 8: Effect of reflection coefficient for the different length of ground slit $L_{2}$.

the $F_{w}$ from its optimum value $4 \mathrm{~mm}$, the desired operating band is shifted. The full ground plane and wide square slot have no responsibility to create resonance frequency in the target operating band which is shown in Figure 10. By using a slit in the left and a slit in the upper, first and second resonances have created with small impedance bandwidth. But impedance bandwidth is increasing with using the right side slit. Finally, the upper resonance was created with good impedance bandwidth in both lower and upper bands using down slit with other three slits.

For better understanding the excitation behaviour of the proposed antenna, surface current distributions in 2.50, 3.48,

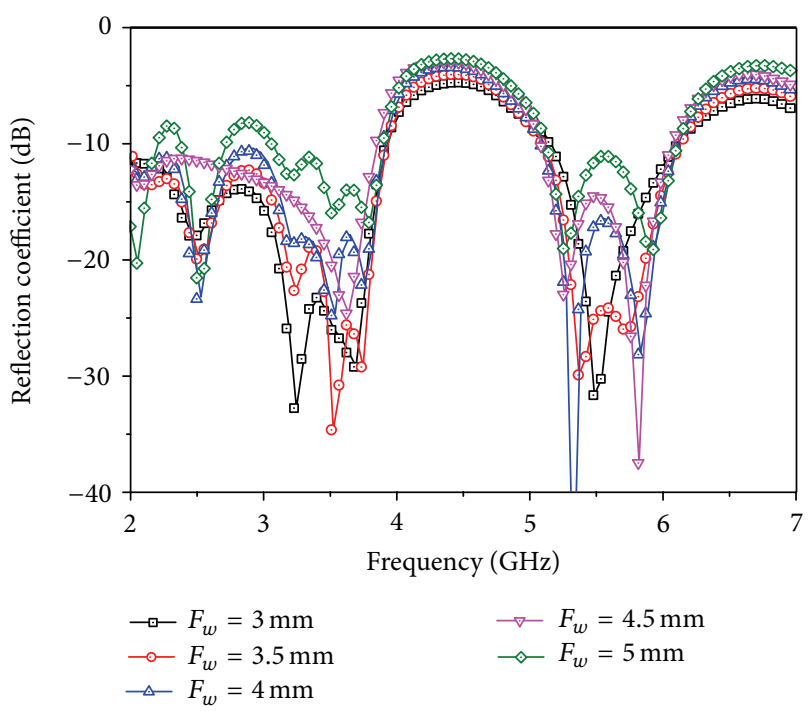

FIGURE 9: Effect of reflection coefficient for the different width of feed line $\left(F_{w}\right)$.

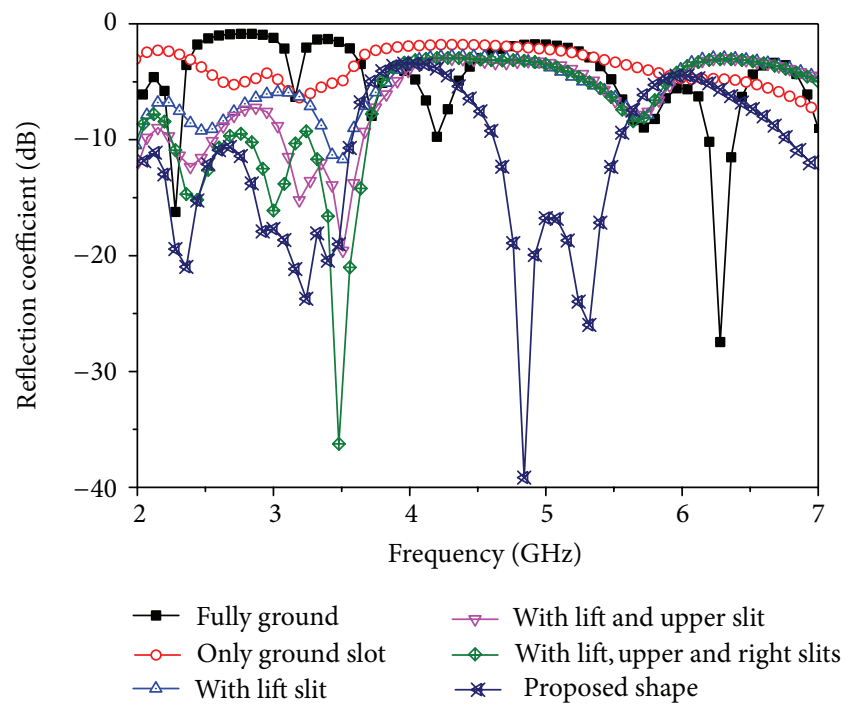

FIGURE 10: Effect of reflection coefficient for ground plane modification.

and 5.30 GHz are studied and displayed in Figure 11. It can be clearly seen from the figure that the current distribution at three resonant frequencies is different. For the first resonant mode, a large surface current density is observed along the whole rectangular Swastika patch slot and the ground plane slit whereas, for the second resonant mode, the current distribution becomes more concentrated along the left side and upper side patch. For the third resonant mode, the current distribution becomes more concentrated along the right side strip and the bottom of Swastika patch. However, they have a common feature that a large surface current density is concentrated along the microstrip feed line. 


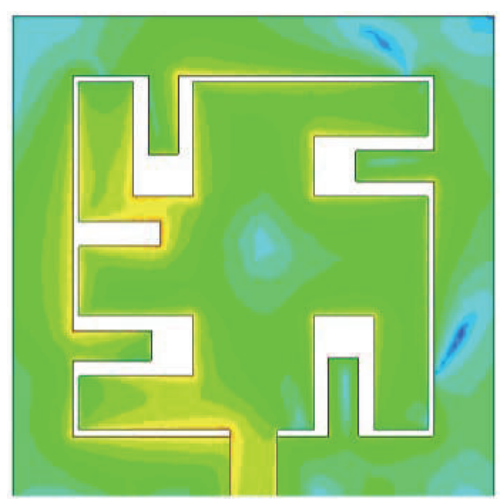

(a)
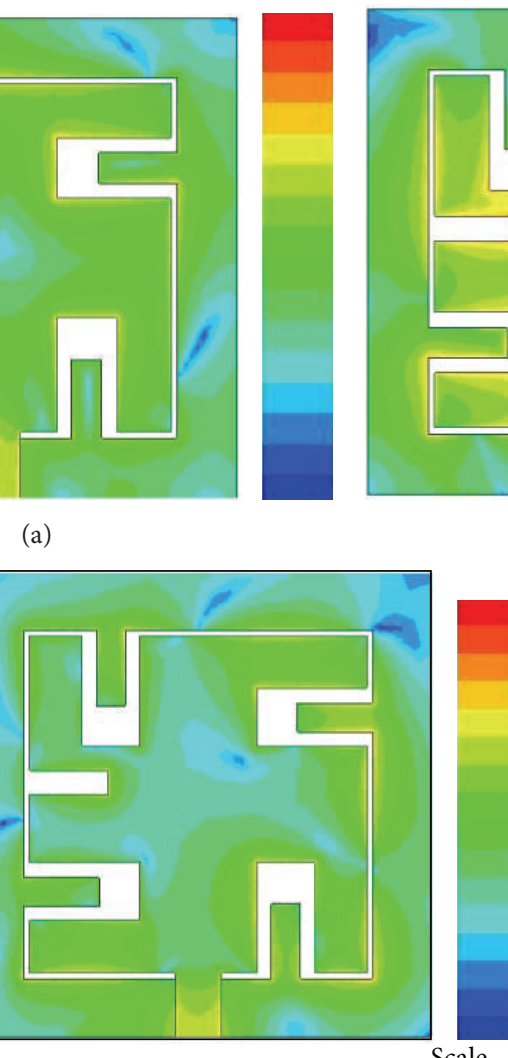

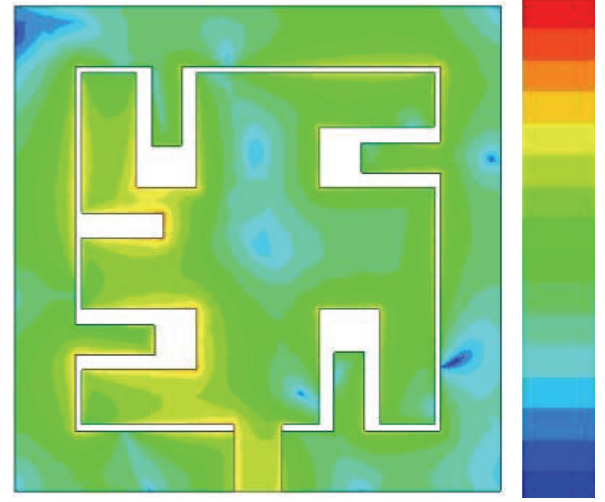

(b)

(c)

FIGURE 11: Simulated surface current distribution of the proposed antenna at (a) $2.50 \mathrm{GHz}$, (b) $3.48 \mathrm{GHz}$, and (c) $5.30 \mathrm{GHz}$.

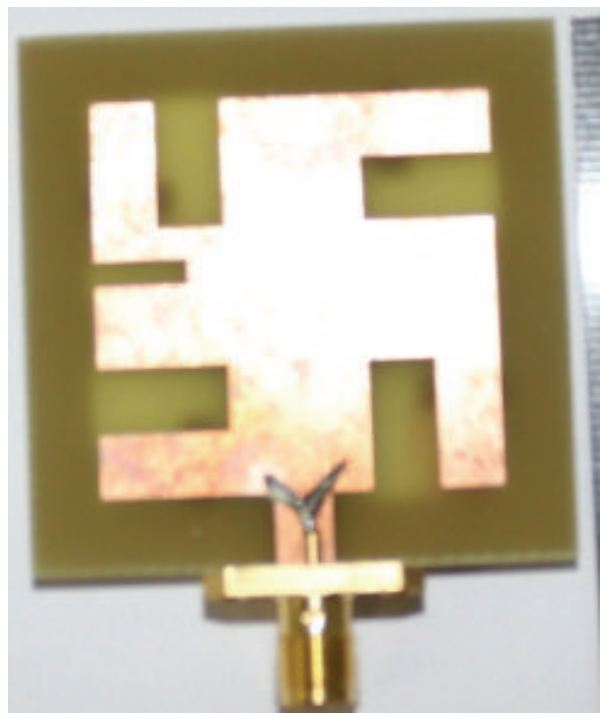

(a)

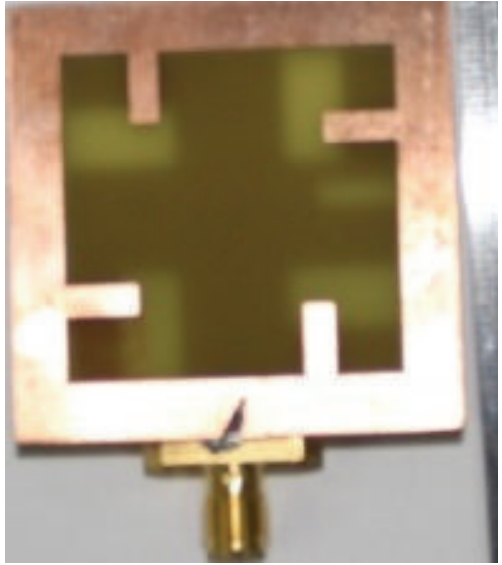

(b)

Figure 12: Fabricated prototype. (a) Top view. (b) Bottom view. 
TABLE 1: Simulated and measured impedance bandwidths of the proposed antenna.

\begin{tabular}{lcccccc}
\hline & \multicolumn{2}{c}{ First resonant mode } & \multicolumn{2}{c}{ Second resonant mode } & \multicolumn{2}{c}{ Third resonant mode } \\
& $f_{c 1}(\mathrm{GHz})$ & Bandwidth $(\mathrm{GHz})$ & $f_{c 2}(\mathrm{GHz})$ & Bandwidth $(\mathrm{GHz})$ & $f_{c 3}(\mathrm{GHz})$ & Bandwidth $(\mathrm{GHz})$ \\
\hline Simulated & 2.50 & $2.0-2.83$ & 3.48 & $2.92-3.89$ & 5.30 & $5.08-6.10$ \\
Measured & 2.44 & $2.28-3.23$ & 3.40 & $3.28-3.94$ & 5.98 & $5.05-6.17$ \\
\hline
\end{tabular}

TABLE 2: Comparison between proposed and some existing antennas.

\begin{tabular}{|c|c|c|c|c|}
\hline Author & Dimension $(\mathrm{mm})$ & Bandwidth (MHz) & Applications & Average peak gain $(\mathrm{dB})$ \\
\hline Proposed & $40 \times 40$ & $\begin{array}{r}950(2280-3230) \\
1120(5050-6170) \\
\end{array}$ & $\begin{array}{c}\text { WLAN } 2.4 / 5.2 / 5.8 \mathrm{GHz} \\
\text { WiMAX 2.5/3.5/5.5 GHz }\end{array}$ & 3.55 and 3.23 \\
\hline$[2]$ & $70 \times 70$ & $\begin{array}{l}540(2205-2745) \\
200(5150-5350) \\
\end{array}$ & 2.4/5.2 WLAN & $1.5,1.1$ \\
\hline$[15]$ & $20 \times 27$ & $\begin{array}{l}150(2370-2520) \\
330(3390-3720) \\
230(5130-5360)\end{array}$ & WLAN $2.4 / 5.2 \mathrm{GHz}$ & $2.4,3.5$, and 1.5 \\
\hline$[16]$ & $30 \times 27$ & $\begin{array}{c}150(2.39-2.54) \\
360(3.37-3.73) \\
1170(5.02-6.19)\end{array}$ & $\begin{array}{l}\text { WLAN }(2.4 / 5.2 / 5.8 \mathrm{GHz}) \\
\text { WiMAX }(3.5 / 5.5 \mathrm{GHz})\end{array}$ & $1.35,1.98$, and 2.6 \\
\hline
\end{tabular}

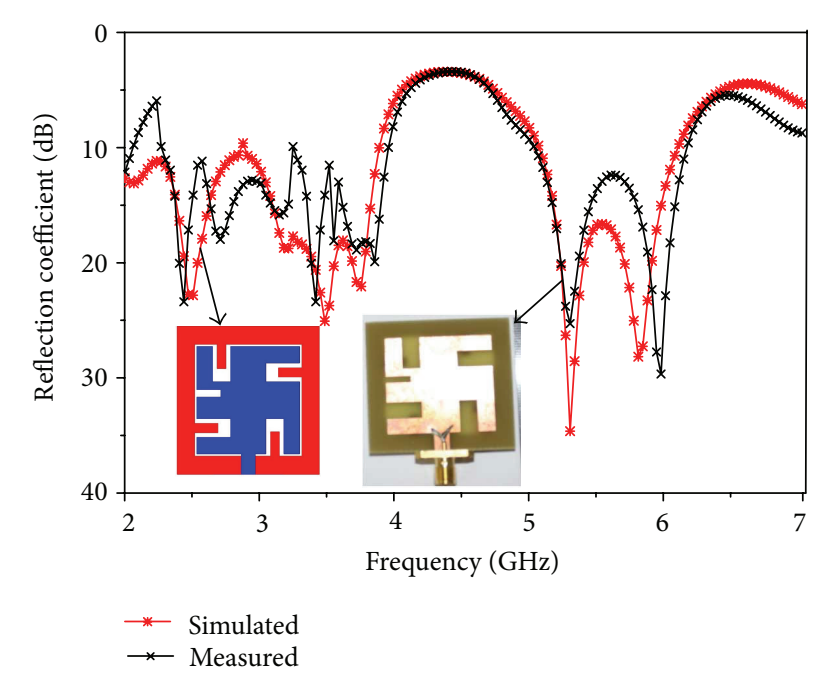

FIGURE 13: Comparison between simulated and measured reflection coefficient of the proposed antenna.

\section{Experimental Results and Discussion}

A prototype of the Swastika shaped patch antenna is fabricated and experimentally investigated based on the optimal dimensions listed in Table 1. Figure 12 shows the photograph of the fabricated antenna. The measured results are performed by using a vector network analyzer and an anechoic chamber. Figure 13 describes the simulated and experimental $S_{11}$ against the frequency of the antenna, where fairly good agreements between them have been achieved. For better comparison, the measured and simulated results are plotted in Figure 13 and listed in Table 1.

The far field radiation properties of the proposed Swastika shape patch antenna are also investigated. Figure 14 depicts the simulated and measured radiation patterns including the vertical and horizontal polarization patterns in the $X$ $Z$ and $Y-Z$ planes of the proposed antenna at 2.44, 3.40, and $5.98 \mathrm{GHz}$ bands, respectively. It can be clearly seen that the proposed antenna shows nearly typical omnidirectional radiation characteristics in the azimuth plane (the $X-Z$ plane) for all frequencies and bidirectional radiation pattern in the elevation plane (the $X-Z$ plane), which depict a monopole like radiation characteristics. This feature is attractive for better transmission capabilities for wireless communication systems in a multipath environment. Moreover, the radiation patterns at other operating frequencies across the bandwidth of each band are very similar to those plotted here; that is, stable radiation patterns have been obtained for the proposed antenna.

The peak antenna gains for frequencies through the matching bands for the proposed antenna are measured and shown in Figure 15. The resonant frequency peak gain of the proposed antenna is $3.97 \mathrm{dBi}$ at $2.44 \mathrm{GHz}, 4.04 \mathrm{dBi}$ at $3.40 \mathrm{GHz}$, and $3.25 \mathrm{dBi}$ at $5.98 \mathrm{GHz}$. This type of antenna gain is good for WLAN/WiMAX applications.

Comparison between proposed and some existing antennas are tabulated in Table 2. From the table it is observed that the proposed antenna has been achieved with wider bandwidth and higher gain with smaller size compared to the reported antennas, although some of the reported antennas have obtained a wide bandwidth and higher gain compromising the overall size.

\section{Conclusion}

A new compact Swastika shaped patch antenna, fed by a microstrip line, is demonstrated for WLAN/WiMAX 

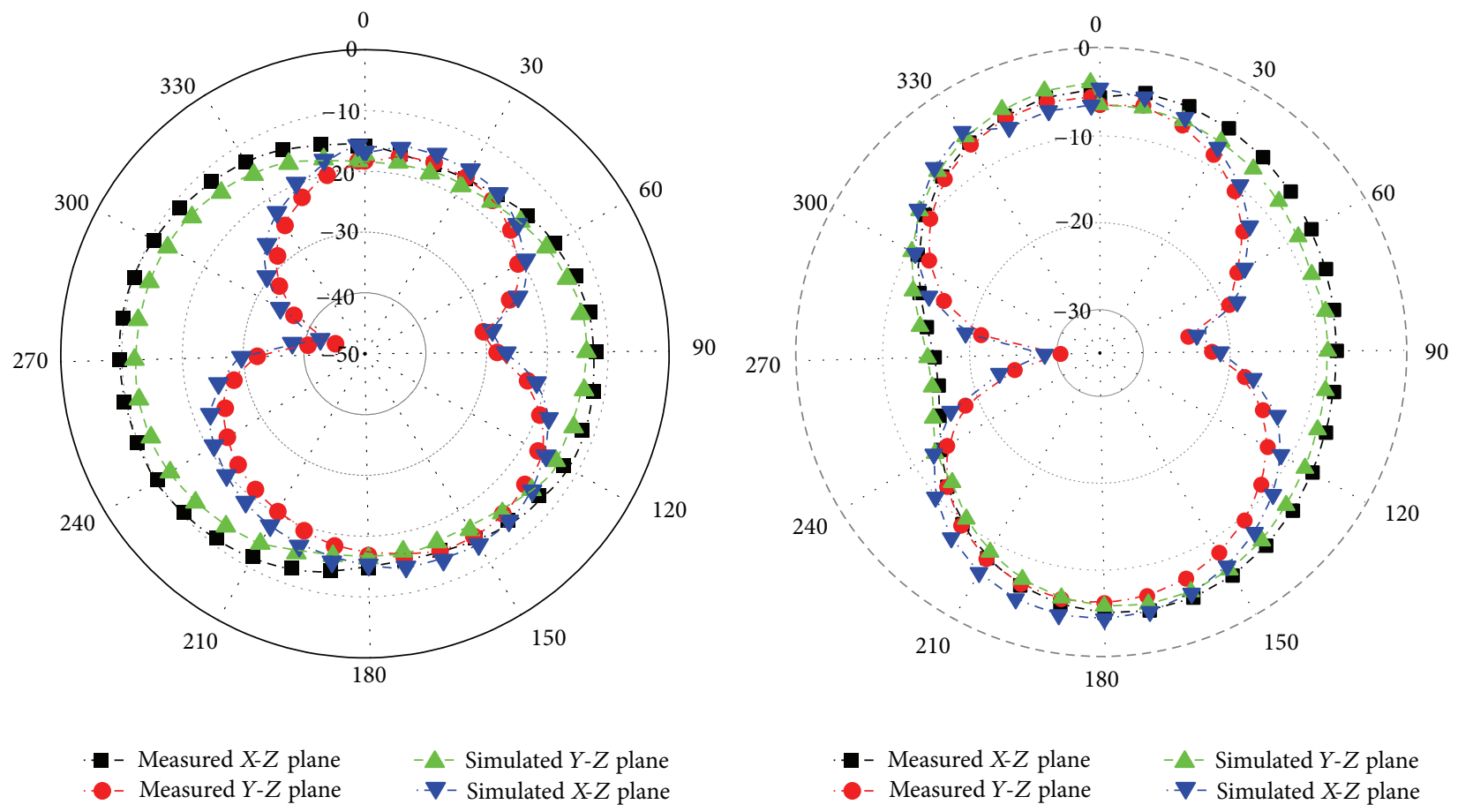

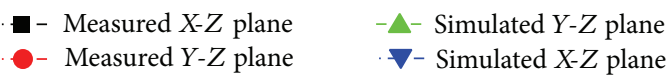

(a)
0

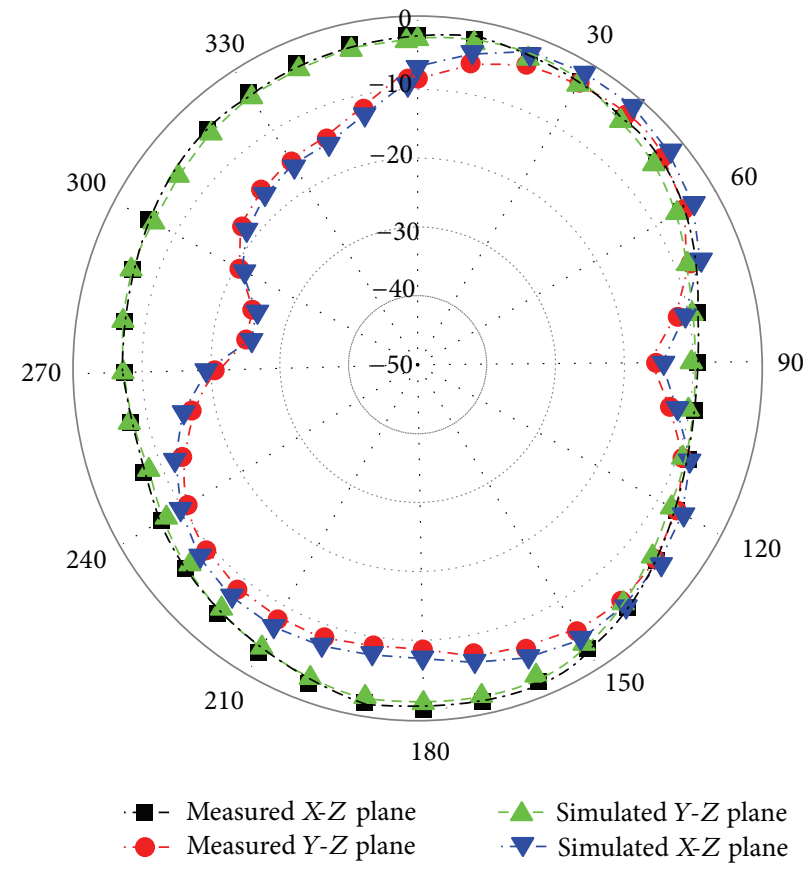

(b)

(c)

FIGURE 14: Radiation pattern of the proposed antenna at (a) $2.44 \mathrm{GHz}$, (b) $3.40 \mathrm{GHz}$, and (c) $5.98 \mathrm{GHz}$.

applications. In the design, by adding an extra slot in the Swastika shape patch and a wide square slot in the ground plane with four extra slits just under the Swastika patch, three resonant modes with good impedance performance are achieved. The measured $-10 \mathrm{~dB}$ impedance bandwidth of the proposed antenna covers 2.28$3.23 \mathrm{GHz}, 3.28-3.94 \mathrm{GHz}$, and $4.76-6.55 \mathrm{GHz}$, which meets the specifications of WLAN2.4/5.2/5.8 GHz and WiMAX 2.5/3.5/5.5 GHz bands. Also, the nearly omnidirectional radiation patterns in the azimuth plane and peak gain of the proposed antenna of $3.97 \mathrm{dBi}$ at $2.44 \mathrm{GHz}, 4.04 \mathrm{dBi}$ at $3.40 \mathrm{GHz}$, and $3.25 \mathrm{dBi}$ at $5.98 \mathrm{GHz}$ are also measured. The proposed antenna would be a good candidate for WLAN/WiMAX wireless communication systems. 


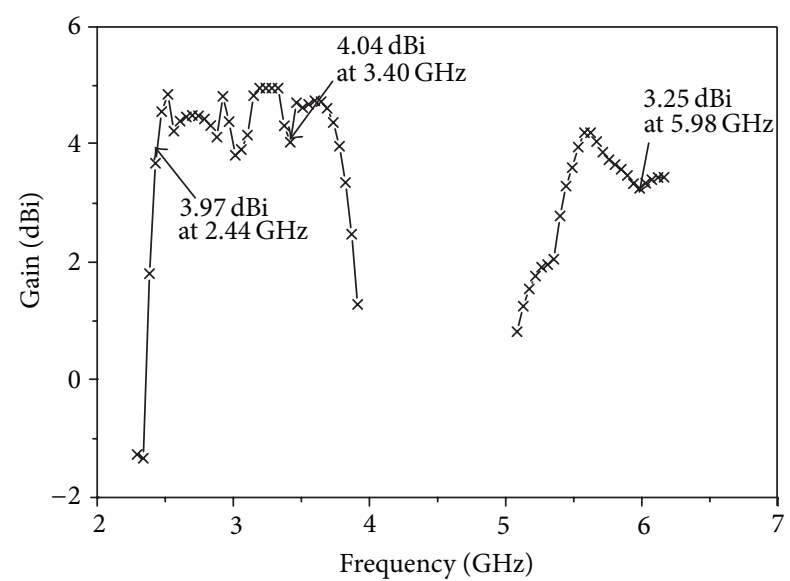

FIGURE 15: Measured gain of the proposed antenna.

\section{Conflict of Interests}

The authors declare that there is no conflict of interests regarding the publication of this paper.

\section{References}

[1] C. A. Balanis, Antenna Theory: Analysis and Design, WileyInterscience, New York, NY, USA, 2012.

[2] Y.-L. Kuo and K.-L. Wong, "Printed double-T monopole antenna for $2.4 / 5.2 \mathrm{GHz}$ dual-band WLAN operations," IEEE Transactions on Antennas and Propagation, vol. 51, no. 9, pp. 2187-2192, 2003.

[3] M. Samsuzzaman, M. T. Islam, and J. S. Mandeep, "Parametric analysis of a glass-micro fibre-reinforced PTFE material, multiband, patch-structure antenna for satellite applications," Optoelectronics and Advanced Materials-Rapid Communications, vol. 7, pp. 760-769, 2013.

[4] J. Zhu, M. A. Antoniades, and G. V. Eleftheriades, "A compact tri-band monopole antenna with single-cell metamaterial loading," IEEE Transactions on Antennas and Propagation, vol. 58, no. 4, pp. 1031-1038, 2010.

[5] R. Azim, M. T. Islam, and N. Misran, "A planar monopole antenna for UWB applications," International Review of Electrical Engineering, vol. 5, no. 4, pp. 1848-1852, 2010.

[6] T. W. Koo, D. Kim, J. I. Ryu, J. C. Kim, and J. Yook, "A coupled dual-u-shaped monopole antenna for WiMAX tripleband operation," Microwave and Optical Technology Letters, vol. 53, no. 4, pp. 745-748, 2011.

[7] R. Azim, M. T. Islam, and N. Misran, "Printed planar antenna for wideband applications," Journal of Infrared, Millimeter, and Terahertz Waves, vol. 31, no. 8, pp. 969-978, 2010.

[8] Y. Han, Y.-Z. Yin, Y.-Q. Wei, Y. Zhao, B. Li, and X.-N. Li, "A novel triple-band monopole antenna with double coupled C-shaped strips for WLAN/WiMAX applications," Journal of Electromagnetic Waves and Applications, vol. 25, no. 8-9, pp. 1308-1316, 2011.

[9] R. Azim, M. T. Islam, N. Misran, S. W. Cheung, and Y. Yamada, "Planar UWB antenna with multi-slotted ground plane," Microwave and Optical Technology Letters, vol. 53, no. 5, pp. 966-968, 2011.
[10] J. Pei, A. Wang, S. Gao, and W. Leng, "Miniaturized triple-band antenna with a defected ground plane for WLAN/WiMAX applications," IEEE Antennas and Wireless Propagation Letters, vol. 10, pp. 298-301, 2011.

[11] F.-C. Ren, F.-S. Zhang, J.-H. Bao, B. Chen, and Y.-C. Jiao, "Compact triple-frequency slot antenna for wlan/wimax operations," Progress in Electromagnetics Research Letters, vol. 26, pp. 21-30, 2011.

[12] L. Liu, S. W. Cheung, R. Azim, and M. T. Islam, "A compact circular-ring antenna for ultra-wideband applications," Microwave and Optical Technology Letters, vol. 53, no. 10, pp. 2283-2288, 2011.

[13] J. Wang, Y. Z. Yin, J. J. Xie, S. L. Pan, J. H. Wang, and X. Lei, “A novel triband circluar ring patch antenna with a symmetrical door-shaped strip for WLAN/Wimax applicaions," Progress in Electromagnetics Research Letters, vol. 34, pp. 137-146, 2012.

[14] T. Wang, Y.-Z. Yin, J. Yang, Y.-L. Zhang, and J. J. Xie, "Compact triple-band antenna using defected ground structure for WLAN/WiMAX applications," Progress in Electromagnetics Research Letters, vol. 35, pp. 155-164, 2012.

[15] Q. Zhao, S.-X. Gong, W. Jiang, B. Yang, and J. Xie, "Compact wide-slot tri-band antenna for WLAN/WiMAX applications," Progress in Electromagnetics Research Letters, vol. 18, pp. 9-18, 2010.

[16] M. Hua, P. Wang, Y. Zheng, and S. Yuan, "Compact tri-band CPW-fed antenna for WLAN/WiMAX applications," Electronics Letters, vol. 49, no. 18, pp. 1118-1119, 2013. 

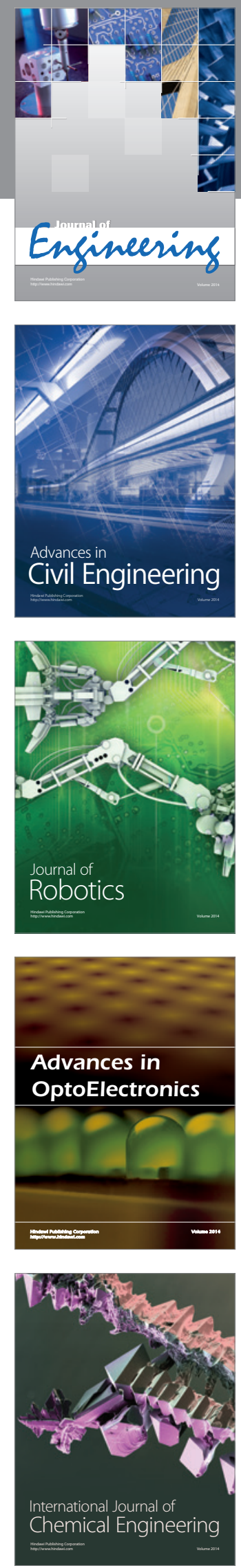

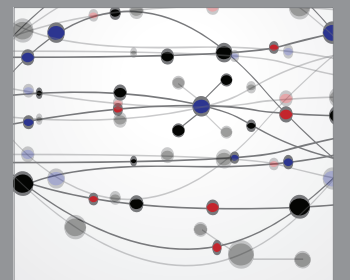

The Scientific World Journal
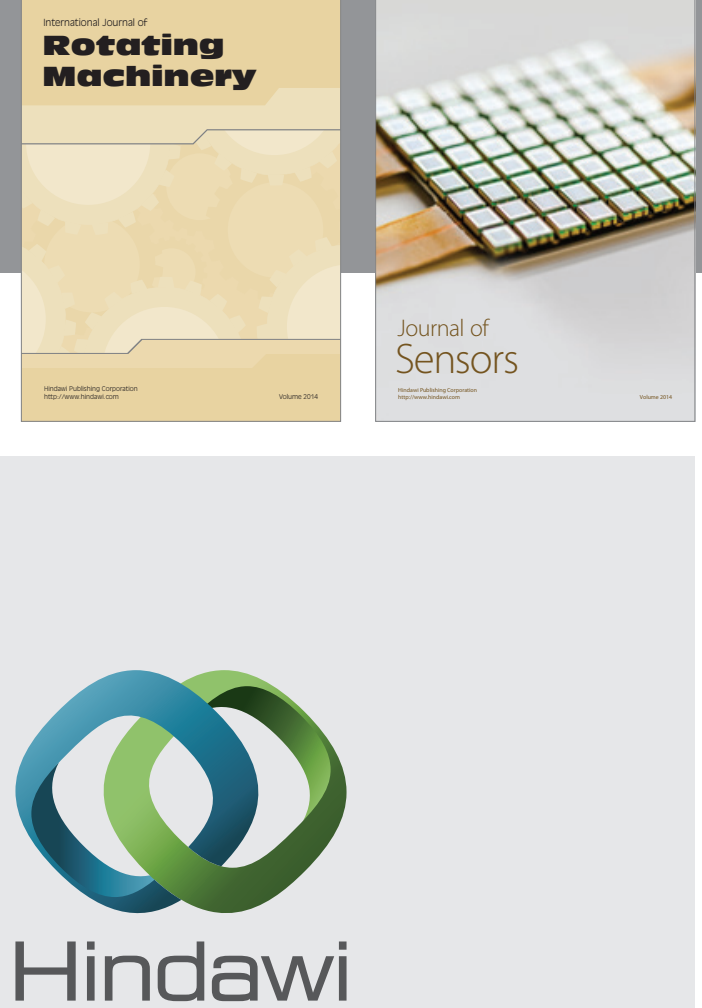

Submit your manuscripts at http://www.hindawi.com
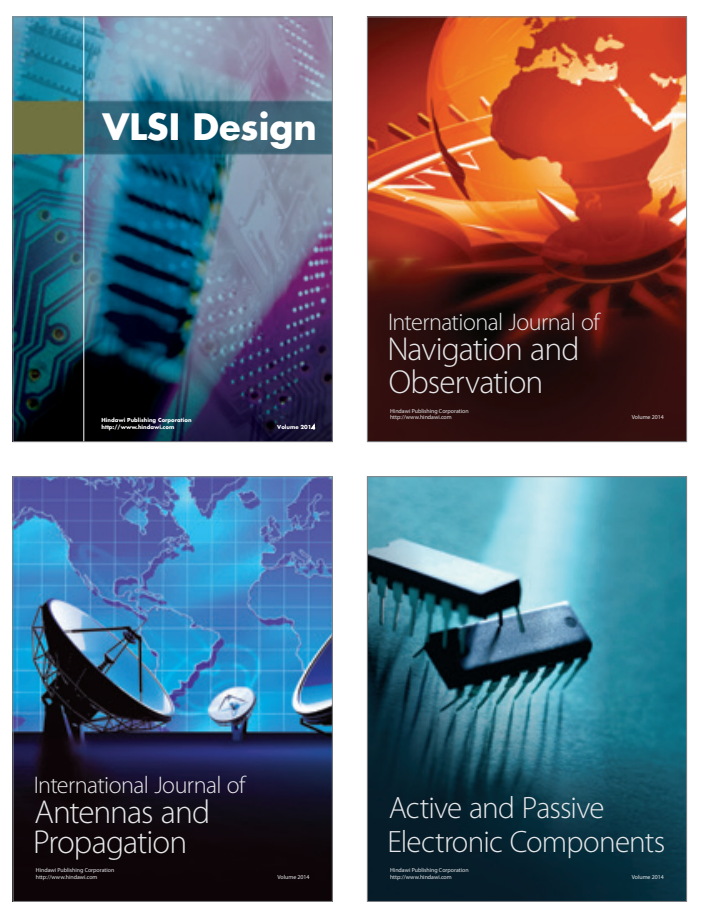
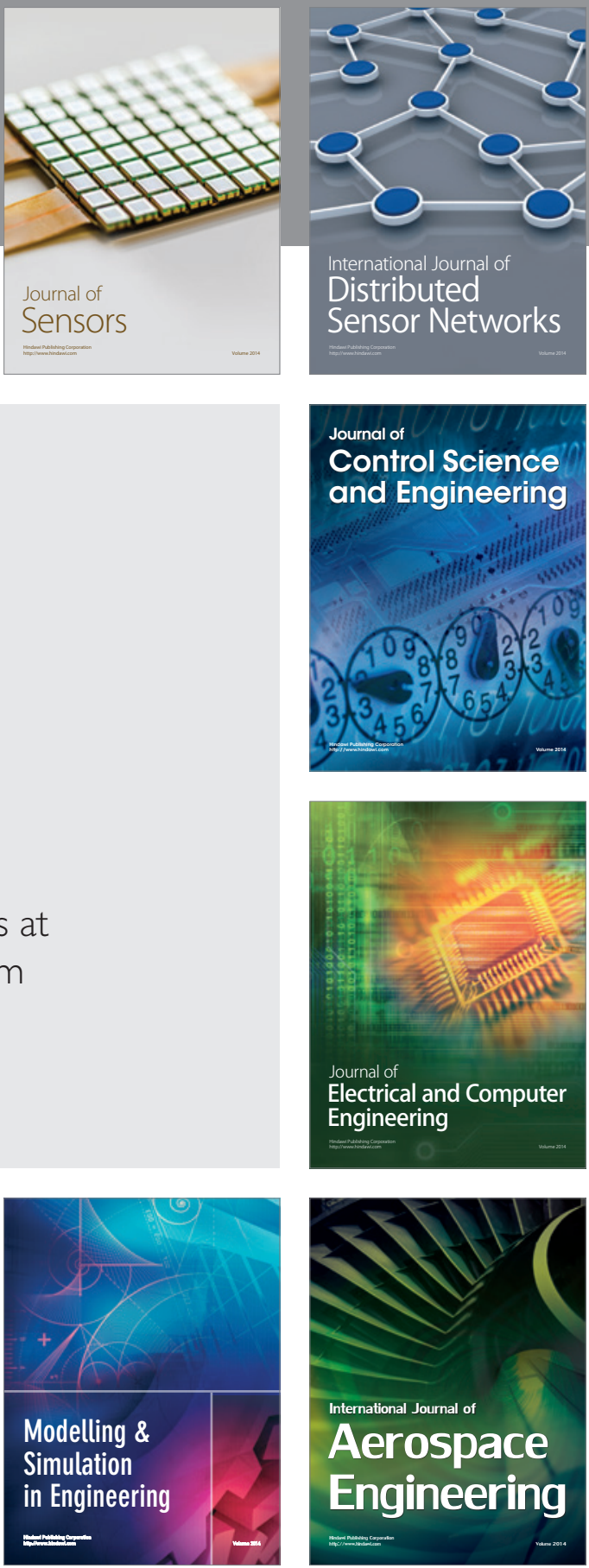

Journal of

Control Science

and Engineering
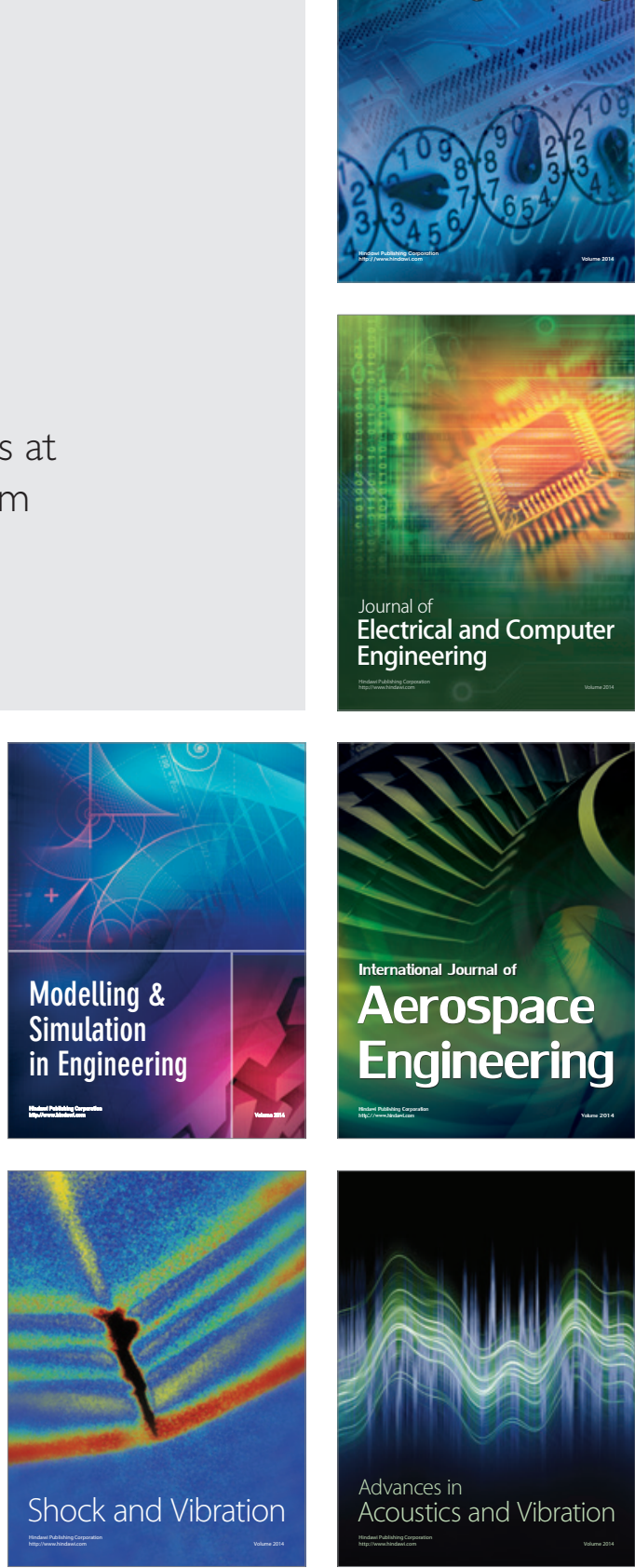